\title{
Study on Corrosion Resistance of N36 Zirconium Alloy in LiOH Aqueous Solution
}

\author{
Chao Sun, Zhongbo Yang, Zongpei Wu \\ Science and Technology on Reactor Fuel and Materials Laboratory, Nuclear Power Institute of China, Chengdu, China \\ Email: yangzhongb@mails.ucas.ac.cn
}

How to cite this paper: Sun, C., Yang, Z.B. and $\mathrm{Wu}$, Z.P. (2018) Study on Corrosion Resistance of N36 Zirconium Alloy in LiOH Aqueous Solution. World Journal of Nuclear Science and Technology, 8, 30-37. https://doi.org/10.4236/winst.2018.82004

Received: February 8, 2018

Accepted: March 30, 2018

Published: April 2, 2018

Copyright $\odot 2018$ by authors and Scientific Research Publishing Inc. This work is licensed under the Creative Commons Attribution International License (CC BY 4.0).

http://creativecommons.org/licenses/by/4.0/

\section{(c) (i) Open Access}

\begin{abstract}
$\mathrm{Zr}-\mathrm{Sn}-\mathrm{Nb}-\mathrm{Fe}$ alloys are one of the important directions for continuous improvement of zirconium alloys for high burn-up fuel assemblies. The corrosion resistance of $\mathrm{Zr}-\mathrm{Sn}-\mathrm{Nb}-\mathrm{Fe}$ alloys is closely related to the alloying element and water chemical condition. To better understand the effect of Sn on corrosion resistance of $\mathrm{Zr}-\mathrm{Sn}-\mathrm{Nb}-\mathrm{Fe}$ alloy, the normal N36 (Zr-1Sn-1Nb-0.3Fe) and low-tin N36 (Zr-0.8Sn-1Nb-0.3Fe) alloy sheets were prepared and tested in static autoclave in both of $0.01 \mathrm{~mol} / \mathrm{L} \mathrm{LiOH}$ and $0.03 \mathrm{~mol} / \mathrm{L} \mathrm{LiOH}$ aqueous solution at $360^{\circ} \mathrm{C}$ and $18.6 \mathrm{MPa}$. The characteristics of the microstructure and oxide film of alloys were analyzed by TEM and SEM respectively. It was shown that that the corrosion transition of the normal N36 appears earlier and the weight gain is higher than the low-tin N36 in two corrosive mediums. The cracks paralleling to the interface of oxide/metal are formed in the fracture surface of the oxide film and the micrographs at the oxide film/substrate interface appear uneven morphology. With the increasing of corrosion gain, there are more parallel cracks in oxide film and the uneven morphology at the oxide film/substrate interface is more obvious.
\end{abstract}

\section{Keywords}

N36 Zirconium Alloy, Corrosion, Oxide Films, Morphology

\section{Introduction}

Zirconium alloys are extensively used to manufacture nuclear reactor components such as fuel claddings, coolant channels, pressure tubes and other in-core structural components due to a low neutron absorption cross section, superior corrosion resistance and high mechanical strength etc. As nuclear reactor technology is gradually developed into the direction at higher burn-up, lower fuel cycle cost, improving thermal efficiency and adding secure reliability, higher re- 
quest for corrosion resistance of zirconium alloys, which are the key components of fuel element cladding materials, is put forward. So many countries have been developing new zirconium alloys cladding materials by optimizing $\mathrm{Zr}-\mathrm{Nb}$ and $\mathrm{Zr}$-Sn series alloys and obtained many $\mathrm{Zr}$-Sn-Nb series new zirconium alloys, such as ZIRLO, E635 and X5A [1] [2] [3], and their corrosion resistance in LiOH aqueous solution are obviously better than Zircaloy- 4 .

The corrosion resistance of zirconium alloy is related to water-chemistry environment and alloy composition. In recent years, with optimizing research [4] [5] about ZIRLO and E635 alloys, it showed the corrosion resistance can greatly increases by reducing Sn content in $\mathrm{Zr}-\mathrm{Sn}-\mathrm{Nb}-\mathrm{Fe}$ alloys, but too little $\mathrm{Sn}$ will lead to accelerated corrosion of alloys in $\mathrm{LiOH}$ aqueous solution, which how to accelerate $\mathrm{Zr}-\mathrm{Sn}-\mathrm{Nb}-\mathrm{Fe}$ alloys corrosion is still obscure at present [6] [7] [8].

$\mathrm{N} 36$ is a new Zr-Sn-Nb-Fe alloy developed by China. Its chemical weight composition was $0.8 \%-1.2 \% \mathrm{Sn}, 0.8 \%-1.2 \% \mathrm{Nb}, 0.2 \%-0.4 \% \mathrm{Fe}, \mathrm{Zr}$ balance, and its nominal composition was $\mathrm{Zr}-1 \mathrm{Sn}-1 \mathrm{Nb}-0.3 \mathrm{Fe}$. To better understand the effect of Sn on accelerated corrosion of N36 alloy in LiOH aqueous solution, the sheet samples of normal N36 (Zr-1Sn-1Nb-0.3Fe) and low-tin N36 (Zr-0.8Sn-1Nb-0.3Fe) were prepared and corroded in static autoclave in both of $0.01 \mathrm{~mol} / \mathrm{L}$ and $0.03 \mathrm{~mol} / \mathrm{L} \mathrm{LiOH}$ aqueous solution at $360^{\circ} \mathrm{C}$ and $18.6 \mathrm{MPa}$. The characteristics of microstructure of alloys, micrographs of the fracture surface and the interface of oxide/metal of the oxide film were analyzed. The effect and mechanism of Sn content on corrosion resistance of N36 zirconium alloy in $\mathrm{LiOH}$ aqueous solution were discussed.

\section{Experiments}

First, the button ingots of normal N36 and low-tin N36 alloy were prepared by vacuum non-consumable arc melted method, each ingot is about $70 \mathrm{~g}$. Next, the ingots were treated by water quench after solid solution treatment at $1050^{\circ} \mathrm{C}$ for $0.5 \mathrm{~h}$, hot rolled after $600^{\circ} \mathrm{C}$ and holding this temperature for $1 \mathrm{~h}$ and cold rolled for 2 times, the alloys were inter-annealed during cold rolling with $600^{\circ} \mathrm{C}$ for $1 \mathrm{~h}$ and final-annealed with $580^{\circ} \mathrm{C}$ for $2 \mathrm{~h}$, The thickness of about $0.6 \mathrm{~mm}$ sheets were finally obtained. The contents of the main element, $\mathrm{O}$ and $\mathrm{N}$ in alloy were showed in Table 1.

The sheets samples were cut into $25 \mathrm{~mm} \times 15 \mathrm{~mm}$. Corrosion tests were conducted in static autoclave in both of $0.01 \mathrm{~mol} / \mathrm{L}$ aqueous solution and $0.03 \mathrm{~mol} / \mathrm{L}$ $\mathrm{LiOH}$ aqueous solution at $360^{\circ} \mathrm{C}$ and $18.6 \mathrm{MPa}$. The JEM-200CX transmission electron microscope was used to analysis the characteristics of grains and the

Table 1. Chemical composition of N36 alloy specimens (wt\%).

\begin{tabular}{ccccccc}
\hline Specimens & $\mathrm{Sn}$ & $\mathrm{Nb}$ & $\mathrm{Fe}$ & $\mathrm{O}$ & $\mathrm{N}$ & $\mathrm{Zr}$ \\
\hline Normal N36 & 1.05 & 0.99 & 0.29 & 0.10 & $<0.006$ & Bal. \\
Low-tin N36 & 0.82 & 0.98 & 0.29 & 0.10 & $<0.006$ & Bal. \\
\hline
\end{tabular}


second phase particles of alloys. The FEI Nova Nano SEM 400 scanning electron microscope was used to observe the fracture of oxide films and interface morphology.

\section{Experimental Results}

\subsection{Microstructure}

Figure 1 shows the TEM microstructure of the final annealing normal N36 (Figure 1(a)) and low-tin N36 (Figure 1(b)) samples respectively, the approximately equal recrystallization grain size are found in both of samples, and the second phase particles (SPPs) take on small round pellets and distributed uniformly in $\alpha$-Zr with the majority SPPs located inside of crystal grain while less is on the boundary, the average size of SPPs were is about $80 \mathrm{~nm}$, which indicate that the Sn content with small adjustment will hardly impact on the recrystallization grain size and the size distribution of SPPs of N36 alloy.

\subsection{Corrosion Behavior}

Figure 2 illustrates the corrosion dynamic curves of normal N36, low-tin N36 and reference $\mathrm{Zr}-4$ alloy samples corroded in both of $0.01 \mathrm{~mol} / \mathrm{L}$ aqueous solution (Figure $2(\mathrm{a})$ ) and $0.03 \mathrm{~mol} / \mathrm{L} \mathrm{LiOH}$ aqueous solution (Figure $2(\mathrm{~b})$ ) at $360^{\circ} \mathrm{C}$ and 18.6 MPa. The corrosion transition of normal N36 and low-tin N36 alloys was found in each $\mathrm{LiOH}$ condition, and the corrosion weight increased swiftly to show corrosion rate speed up after corrosion transition. Among three alloy samples, the low-tin N36 alloy, whose happened time of corrosion transition is the latest in same water-chemical condition and corrosion weight is the lowest after long-term corrosion, and compared with normal N36 alloy, the time of corrosion transition of $\mathrm{Zr}-4$ alloy is earlier and the corrosion weight is higher. When water-chemical environment differ from $\mathrm{LiOH}$ concentration, the best corrosion resistance is low-tin N36, following is normal N36, while the worst is $\mathrm{Zr}-4$.

\subsection{Fracture Morphology}

Figure 3 shows the fracture morphology of normal N36 (Figure 3((a), (a1))) and low-tin N36 (Figure 3((b), (b1))) samples corroded in $0.01 \mathrm{~mol} / \mathrm{L}$ aqueous solution at $360^{\circ} \mathrm{C}$ and $18.6 \mathrm{MPa}$ for 370 days, respectively. The cracks paralleling

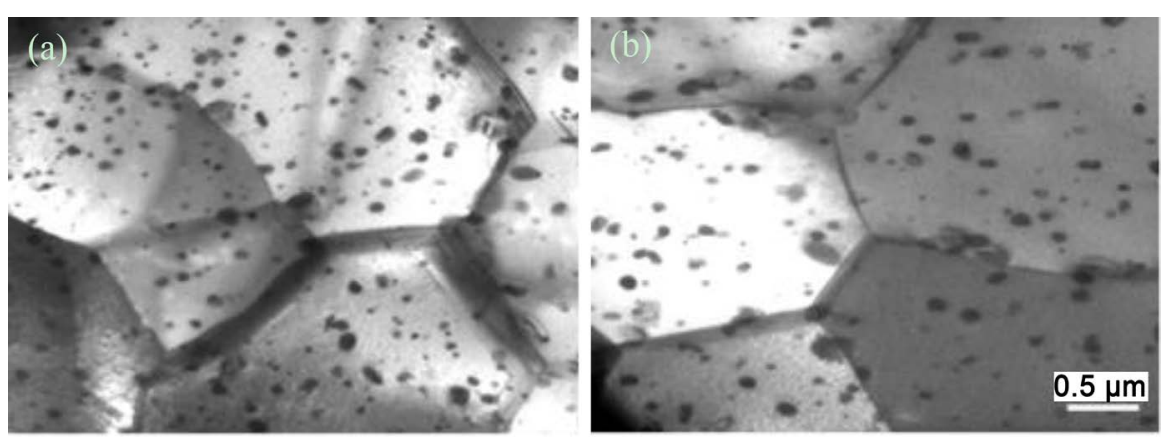

Figure 1. TEM graphs of N36 alloy (a) normal N36 and (b) low-tin N36. 

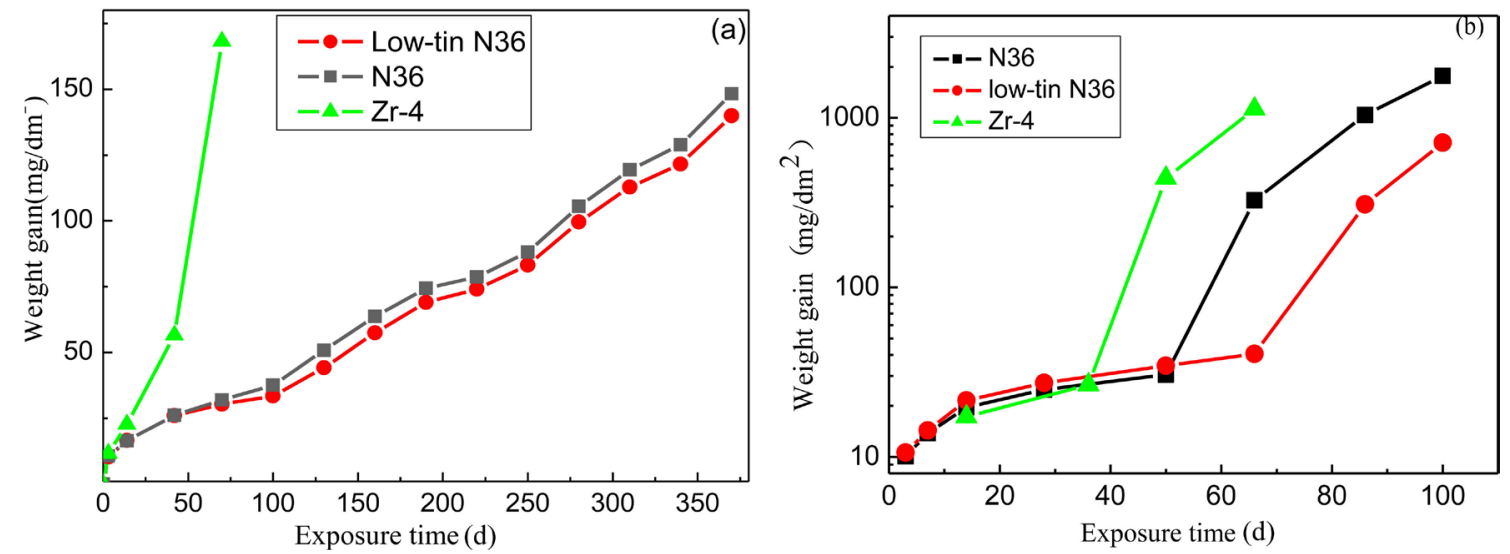

Figure 2. Corrosion dynamic curves of normal N36, low-tin N36 and reference Zr-4 alloy samples corroded in (a) $0.01 \mathrm{~mol} / \mathrm{L} \mathrm{LiOH}$ aqueous solution and (b) $0.03 \mathrm{~mol} / \mathrm{L} \mathrm{LiOH}$ aqueous solution at $360^{\circ} \mathrm{C}$ and $18.6 \mathrm{MPa}$.
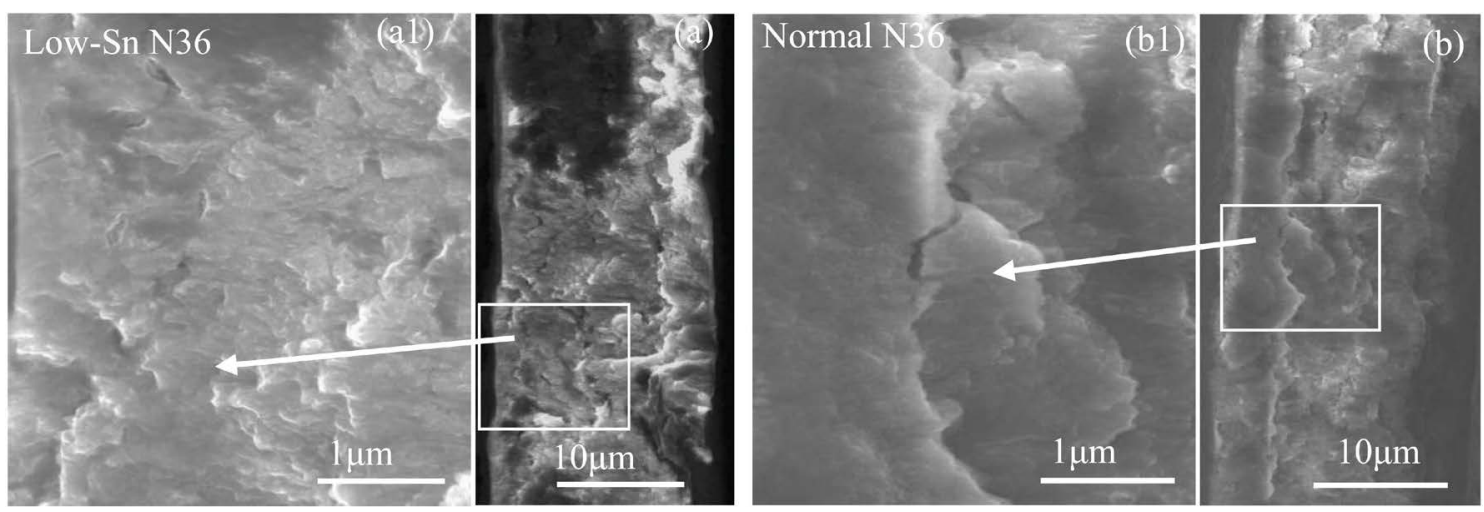

Figure 3. Oxide film fracture micrographs of low-tin N36 ((a), (a1)) and normal N36 ((b), (b1)) alloys corroded in $0.01 \mathrm{~mol} / \mathrm{L} \mathrm{LiOH}$ aqueous solution at $360^{\circ} \mathrm{C}$ and $18.6 \mathrm{MPa}$ for 370 days exposure.

to the interface of oxide/metal are formed in the fracture surface of the oxide film, and there was not significant difference of cracks between normal and N36 low-tin N36, the cause was ascribed to little difference of weight gains between N36 alloys.

Figure 4 shows oxide films fracture appearance of low-tin N36 and normal $\mathrm{N} 36$ alloys corroded in the $0.03 \mathrm{~mol} / \mathrm{L} \mathrm{LiOH}$ solution at $360^{\circ} \mathrm{C}$ and $18.6 \mathrm{MPa}$ for 86 days. The oxide film fracture of low-tin N36 alloy appears more compact than normal N36 alloy, and there are more flaws or cracks which paralleled to the oxide films/metal in fracture of normal N36 alloy.

After corrosion for 100 days, the oxide films fracture in low-tin N36 and normal N36 alloys appear laminar cracks(Figure 5), it also have flaws close to metal base. Compared to low-tin N36, normal N36 alloy has more laminar cracks as well as more narrow cracks interval.

Figure 6 shows the micrographs at the oxide film/substrate interface of low-tin N36 and normal N36 corroded in $0.03 \mathrm{~mol} / \mathrm{L} \mathrm{LiOH}$ aqueous solution at $360^{\circ} \mathrm{C}$ and 18.6 MPa for 100 days exposure. The oxide films exist cauliflower-like structure with many gaps which showed as pore in high magnification. Compared with low-tin N36, the oxide film of normal N36 alloy appear much more 

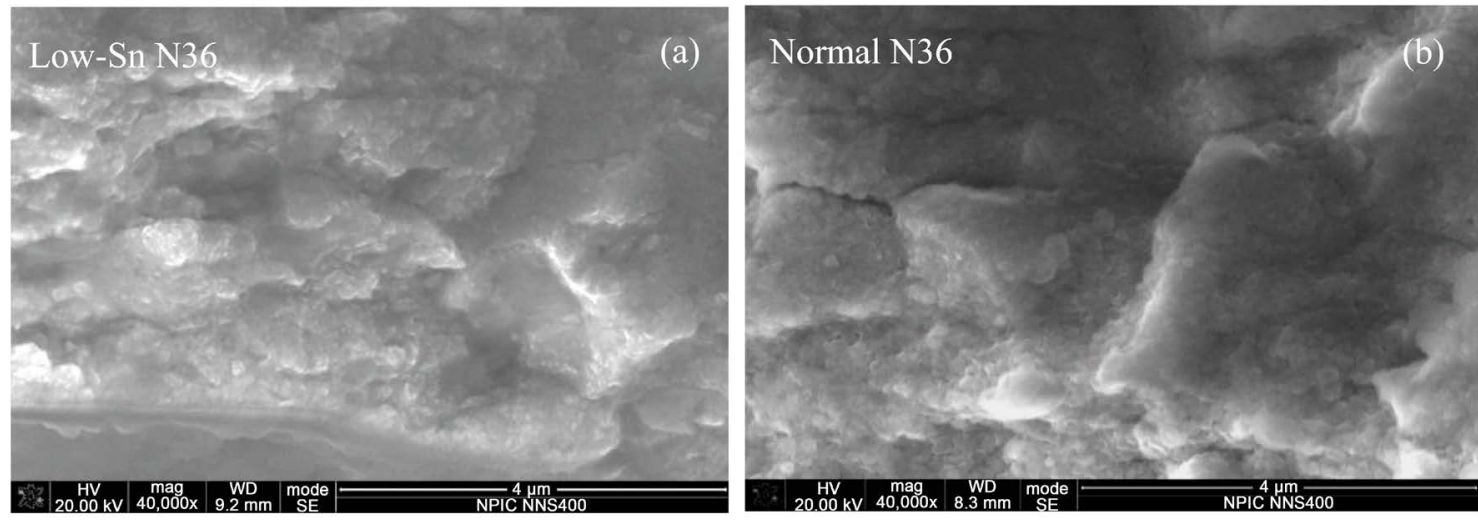

Figure 4. Oxide film fracture micrographs of low-tin N36 (a) and normal N36 (b) alloys corroded in $0.03 \mathrm{~mol} / \mathrm{L}$ $\mathrm{LiOH}$ aqueous solution at $360^{\circ} \mathrm{C}$ and $18.6 \mathrm{MPa}$ for 86 days exposure.
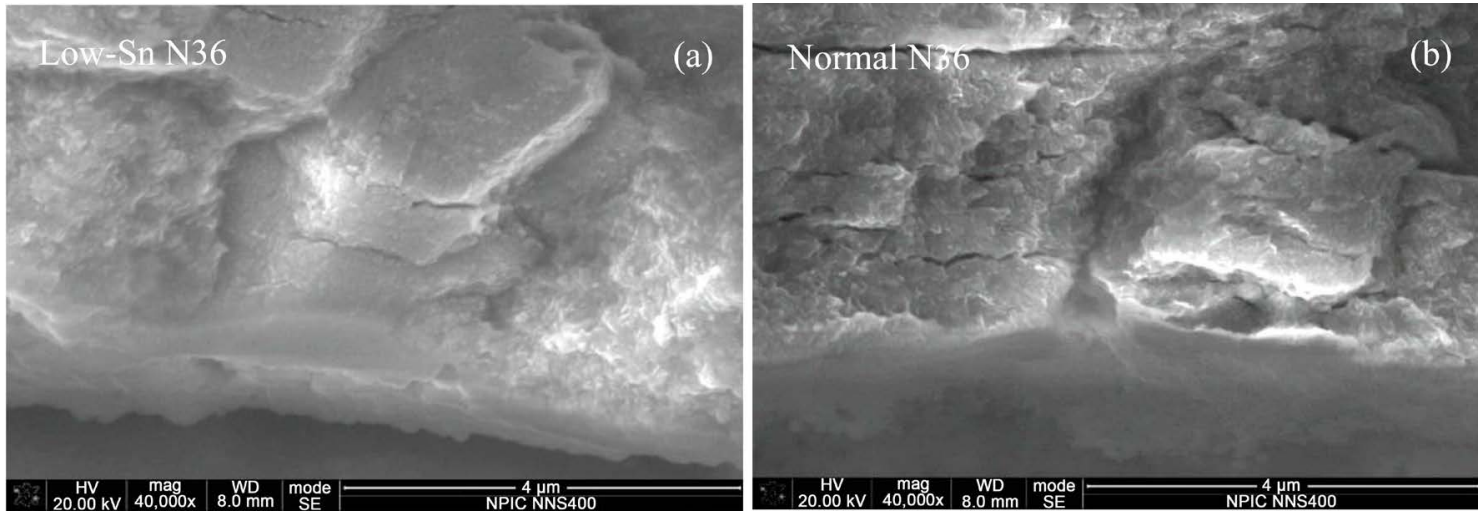

Figure 5. Oxide film fracture micrographs of low-tin N36 (a) and normal N36 (b) alloys corroded in 0.03 mol/L $\mathrm{LiOH}$ aqueous solution at $360^{\circ} \mathrm{C}$ and $18.6 \mathrm{MPa}$ for 100 days exposure.
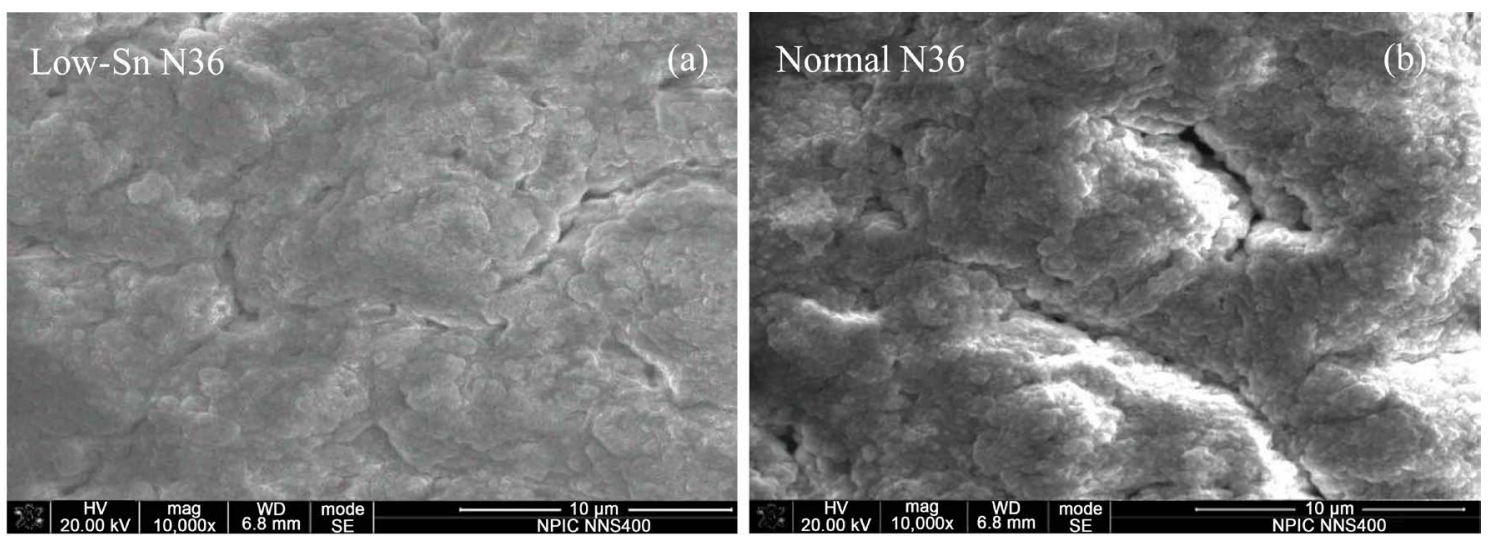

Figure 6. The micrographs at the oxide film/substrate interface of low-tin N36 (a) and normal N36 (b) alloys corroded in $0.03 \mathrm{~mol} / \mathrm{L} \mathrm{LiOH}$ aqueous solution at $360^{\circ} \mathrm{C}$ and $18.6 \mathrm{MPa}$ for 100 days exposure.

uneven as well as bigger pore dimensions.

\section{Analysis and Discussions}

According to corrosion dynamics curves of $\mathrm{Zr}-4$, normal N36 and low-tin alloy specimens corroded in both of $0.01 \mathrm{~mol} / \mathrm{L}$ aqueous solution and $0.03 \mathrm{~mol} / \mathrm{L}$ 
$\mathrm{LiOH}$ aqueous solution at $360^{\circ} \mathrm{C}$ and $18.6 \mathrm{MPa}$, the corrosion resistance of normal N36 and low-tin N36 are better than Zr-4 alloy while low-tin N36 alloy are better than normal N36 alloy. The corrosion behavior of zirconium alloy is related to alloy composition and microstructure. As a relatively stable element of $\alpha$-Zr, Sn exist in $\alpha$ - Zr through solid solution atom. The average size of the second phase particles will increase little as the content of Sn increase and effect the corrosion behavior of alloy [9]. But crystal structure, the size of second phase particles as well as distribution have not obviously distinction by judge from microstructure of normal N36 and low-tin N36 zirconium alloy as the content of $\mathrm{Sn}$ in two alloys have little difference, on the other side, heat treatment temperature $\left(580^{\circ} \mathrm{C}-600^{\circ} \mathrm{C}\right)$ of alloy specimens is far more lower than transfer temperature of N36 alloy [1]. the second phase particles of N36 alloy are C14 Zr (Fe, $\mathrm{Nb})_{2}$ and $\beta$ - $\mathrm{Nb}[10]$, so the size of second phase particles, distribution and type are very close before corrosion, it is not the main reason that cause the difference in corrosion resistance between N36 and low-tin N36.

According to the observing results of microstructure of oxide films after corrosion, the corrosion behavior of N36 alloys with little difference in Sn content have a certain corresponding relation with the quantity of parallel cracks in oxide films fracture. For good corrosion resistance of low-tin N36 alloys, cracks which parallel the oxide film/substrate interface is relatively less, while there are more parallel cracks in normal N36 with poor corrosion resistance. Cracks gaps are in inverse proportion to corrosion rate after corrosion transition, which promote the growth of oxide films. So the oxide films are thicker at the same corrosion time. On the other hand, the fracture of low-tin N36 alloy specimens corroded in $0.03 \mathrm{~mol} / \mathrm{L} \mathrm{LiOH}$ aqueous solution for 86 days have not obviously cracks, and its surface inside oxide films are more smooth than normal N36, it is indicated the oxide films growth rate at metal base is not even, which lead to uneven inner surface. The inner surface of oxide films shape in cauliflower-like uneven related with oxide film existing obvious cracks [11] [12].

The cracks and pores in oxide films are related with gathering and release of stress during the growth of oxide films. As zirconium alloys are corroded at initial stage, the oxide films grow at the stable tetragonal $\mathrm{ZrO}_{2}$, and volume expand ( $\mathrm{P}-\mathrm{B}$ ratio 1.56), it is also constrained by matrix metal and have stable function to tetragonal because there will be compressive stress inside the oxide films [13]. Along with adding distance to fracture, the compressive stress of inner oxide films become weak so that cause tetragonal $\mathrm{ZrO}_{2}$ to transfer monoclinic $\mathrm{ZrO}_{2}$ during transference, at the same time, in the vicinity of transient $\mathrm{ZrO}_{2}$ produce internal stress which shape cracks in the oxide films and shorten distribution route of $\mathrm{H}$ or $\mathrm{O}$ and decrease corrosion resistance of alloy [14] [15]. So it is also concluded that when oxide films of good corrosion resistance low-tin N36 exist in tetragonal $\mathrm{ZrO}_{2}$.

The tin as solid solute in $\alpha$-Zr diffuse and gather in the interfacial boundary of tetragonal $\mathrm{ZrO}_{2}$ at a specific temperature and compressive stress. During corro- 
sion process of alloy specimens, the enriched tin at the crystal boundary expand when they are oxidized, which will make the $\mathrm{t}-\mathrm{ZrO}_{2}$ change into $\mathrm{m}-\mathrm{ZrO}_{2}$ with greater speed, and accelerate to produce cracks [16]. So low-tin N36 alloy with little Sn have little cracks in its oxide films and have good corrosion resistance.

\section{Conclusion}

1) Compared to $\mathrm{Zr}-4$ alloy, the corrosion resistance of $\mathrm{N} 36$ alloy are better in both of $0.01 \mathrm{~mol} / \mathrm{L} \mathrm{LiOH}$ aqueous solution and $0.03 \mathrm{~mol} / \mathrm{L} \mathrm{LiOH}$ aqueous solution at $360^{\circ} \mathrm{C}$ and $18.6 \mathrm{MPa}$, while low-tin $\mathrm{N} 36$ is better than normal N36.

2) The little difference of Sn content hardly influences on grain size and precipitates of the N36 alloys. It was concluded that the solid solution contents of $\mathrm{Sn}$ in a-Zr matrix was the main reason cause corrosion resistance difference between normal N36 and low-tin N36.

3) As samples corroded in different water chemistry, the cracks paralleling to the interface of oxide/metal are formed in the fracture surface of the oxide film and the oxide film in the inner surface appears at the Cauliflower-like morphology after corrosion transition. With the increasing of corrosion rate, there are more cracks in the fracture surface of the oxide film and the size of Cauliflower-like structure grows bigger.

\section{References}

[1] Zhao, W.J., Liu, Y.Z., Jiang, H.M., et al. (2008) Effect of Heat Treatment and Nb and $\mathrm{H}$ Contents on the Phase Transformation of N18 and N36 Zirconium Alloys. Journal of Alloys and Compounds, 462, 103-108. https://doi.org/10.1016/j.jallcom.2007.08.047

[2] Zhang, X., Yao, M.Y., Li, Z.K., et al. (2013) Corrosion Resistance of $\mathrm{Zr}-0.80 \mathrm{Sn}-0.4 \mathrm{Nb}-0.4 \mathrm{Fe}-0.10 \mathrm{Cr}-\mathrm{xCu}$ Alloys in Super-Heated Steam at $400^{\circ} \mathrm{C}$. Rare Metal Materials and Engineering, 42, 1210-1214.

[3] Comstock, A.M., Pan, R.J., Garde, G., et al. (2010) Advanced Zirconium Alloys for PWR Application. Journal of ASTM International, 7, 1546.

[4] Yang, Z.B., Zhao, W.J., Miao, Z., et al. (2015) Corrosion Behavior of Zr-XSn-1Nb-0.3Fe Alloys. Rare Metal Materials and Engineering, 44, 1129-1133.

[5] Zhang, J.L., Xie, X.F., Yao, M.Y., et al. (2013) Study on the Corrosion Resistance of $\mathrm{Zr}-1 \mathrm{Nb}-0.7 \mathrm{Sn}-0.03 \mathrm{Fe}-\mathrm{xGe}$ Alloy in Lithiated Water at $360^{\circ} \mathrm{C}$. Acta Metallurgica Sinica, 49, 443-450. https://doi.org/10.3724/SP.J.1037.2012.00638

[6] Park, J.Y., Yoo, S.J., Choi, B.K., et al. (2008) Corrosion and Oxide Characteristics of $\mathrm{Zr}-1.5 \mathrm{Nb}-0.4 \mathrm{Sn}-0.2 \mathrm{Fe}-0.1 \mathrm{Cr}$ Alloy in $360^{\circ} \mathrm{C}$ Pure Aqueous and $\mathrm{LiOH}$ Solution. Journal of Nuclear Materials, 37, 343-350. https://doi.org/10.1016/j.jnucmat.2007.06.015

[7] Yao, M.Y., Zhou, B.X., Li, Q., et al. (2008) A Superior Corrosion Behavior of Zircaloy-4 in Lithiated Aqueous at $360^{\circ} \mathrm{C} / 18.6 \mathrm{MPa}$ by $\beta$-Quenching. Journal of Nuclear Materials, 374, 197-203. https://doi.org/10.1016/j.jnucmat.2007.08.002

[8] Zhang, H.X., Fruchart, D., Hlil, E.K., et al. (2010) Crystal Structure, Corrosion Kinetics of New Zirconium Alloys and Residual Stress Analysis of Oxide Films. Journal of Nuclear Materials, 396, 65-70. https://doi.org/10.1016/j.jnucmat.2009.10.055

[9] Takeda, K. and Anada, H. (2000) Mechanism of Corrosion Rate Degradation due to 
Tin. Journal of ASTM International, 5, 592.

[10] Yilmazbayhan, A., Breval, E., Motta, A.T., et al. (2006) Transmission Electron Microscopy Examination of Oxide Layers Formed on Zr Alloys. Journal of Nuclear Materials, 34, 265-281. https://doi.org/10.1016/j.jnucmat.2005.10.012

[11] Zhang, J.L., Tu, L.M., Xie, X.F., et al. (2014) Corrosion Resistance of Zr-1Nb-xGe Alloys in Superheated Steam at $400^{\circ} \mathrm{C}$. Journal of the Chinese Society of Corrosion and Protection, 34, 171-177.

[12] Gholinia, G.A., Frankel, P., et al. (2014) The Microstructure and Microtexture of Zirconium Oxide Films Studied by Transmission Electron Backscatter Diffraction and Automated Crystal Orientation Mapping with Transmission Electron Microscopy. Acta Materialia, 80, 159-171. https://doi.org/10.1016/j.actamat.2014.07.062

[13] Bossis, P., Thomazet, J., Lefebvre, F., et al. (2002) Study of the Mechanisms Controlling the Oxide Growth under Irradiation: Characterization of Irradiated Zircaloy-4 and $\mathrm{Zr}-1 \mathrm{Nb}-\mathrm{O}$ Oxide Scales. International Journal of Environmental Analytical Chemistry, 89, 67-82. https://doi.org/10.1520/STP11390S

[14] Platt, P., Frankel, P., Gass, M., et al. (2015) Critical Assessment of Finite Element Analysis Applied to Metal-Oxide Interface Roughness in Oxidising Zirconium Alloys. Journal of Nuclear Materials, 464, 313-319. https://doi.org/10.1520/STP11390S

[15] Zhang, J.L., Xie, X.F., Yao, M.Y., et al. (2013) Effect of Ge Addition on Corrosion Performance of Zr-4 Alloy in Lithiated Solution. Chinese Journal of Nonferrous Metal, 23, 1542-1548.

[16] Platt, P., Polatidis, E., Frankel, P., et al. (2015) A Study into Stress Relaxation in Oxides Formed on Zirconium Alloys. Journal of Nuclear Materials, 456, 415-425. https://doi.org/10.1016/j.jnucmat.2014.09.072 